Provided for non-commercial research and education use. Not for reproduction, distribution or commercial use.

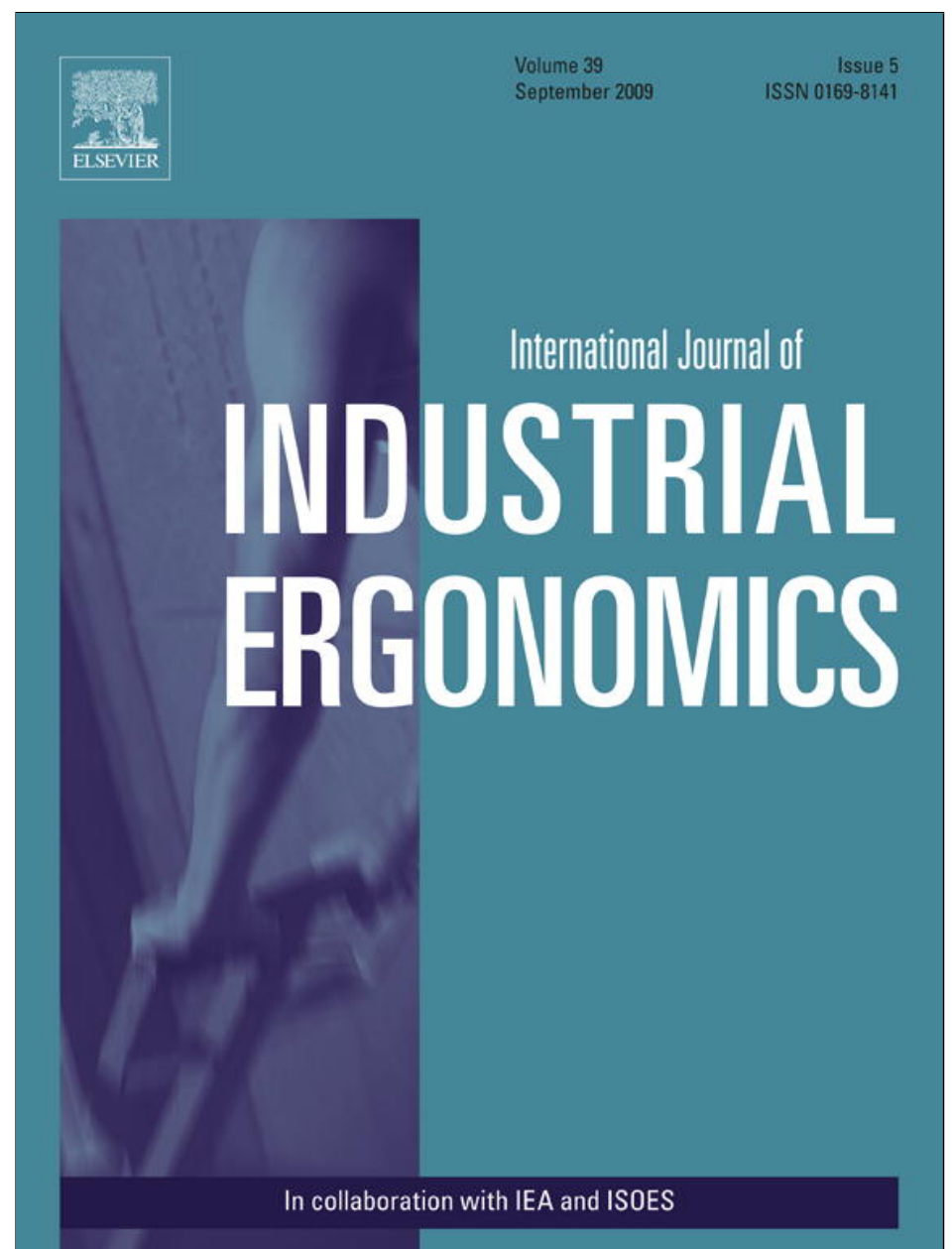

This article appeared in a journal published by Elsevier. The attached copy is furnished to the author for internal non-commercial research and education use, including for instruction at the authors institution and sharing with colleagues.

Other uses, including reproduction and distribution, or selling or licensing copies, or posting to personal, institutional or third party websites are prohibited.

In most cases authors are permitted to post their version of the article (e.g. in Word or Tex form) to their personal website or institutional repository. Authors requiring further information regarding Elsevier's archiving and manuscript policies are encouraged to visit:

http://www.elsevier.com/copyright 


\title{
Influence of occupational stress on the mental health of Ghanaian professional women
}

\author{
Jocelyn Sackey, Mohammed-Aminu Sanda* \\ Department of Organization and Human Resource Management, University of Ghana Business School, P.O. Box LG 78, Legon, Accra, Ghana
}

\section{A R T I C L E I N F O}

\section{Article history:}

Received 27 November 2008

Received in revised form 29 March 2009

Accepted 24 April 2009

Available online 28 May 2009

\section{Keywords:}

Work-related stressors

Mental health

Managerial women

Work environment

\begin{abstract}
A B S T R A C T
Managerial women experience a number of work-related stressors which produce strain symptoms that function as predictors of their ill-health in organizations. This finding is made from a study that examined the existing relationships among job characteristics symptoms of stress, and the development of health outcomes (depression, anxiety and physical symptoms) among women in lower and middle management positions in some organizations in Ghana. The stratified and simple random sampling procedure was used to select the study participants which numbered 170 female managers. Data was collected using both questionnaires and interviews, and analyzed using the Occupational Stress Indicator, the Depression, Anxiety and Stress Scale, and the Beck's Anxiety Inventory. It is concluded that since work-related stressors are predictors of women managers' ill-health in the work environment, organizations should be aware of the stressors in order to be able to guard against the deterioration of job performances of their women managers.

Relevance to Industry: This study highlights the high prices organizations pay for the work-related stresses their women managers experience at the workplace, which impact negatively on their mental health, and by implication their productivity. Recommendations made can be used to enhance the managerial capacity and productivity of female managers at the workplace.
\end{abstract}

(c) 2009 Elsevier B.V. All rights reserved.

\section{Introduction}

As a result of the potential negative consequences of stress and the increasing number of women in the labor force and in managerial positions, research on occupational stress has become a topic of significance to both individuals and organizations. Attaining and safeguarding the health of managerial women is of significance to the effective and profitable continuation of the organization. Organizations have a legal responsibility under law to take reasonable care to ensure that the health of their employees is not placed at risk through excessive and sustained levels of stress (Labor Act, Ghana, 2003). With the growing number of women in management, future productivity may depend on organizations' ability to integrate women into the main stream of organizational life (Offerman and Gowring, 1990). Again, with the growth in information communication and technology, and demands of modern life, many jobs are becoming more complex and cognitively demanding. Pressures at work, coupled with demands of family, have tended to increase the occupational stressors of managerial

\footnotetext{
* Corresponding author. Tel.: +233 275991098; fax: +23321500024

E-mail address: masanda@ug.edu.gh (M.-A. Sanda).
}

women and thereby increasing their chances of developing psychological ailments. It is against this backdrop that the present study was undertaken. This is an interesting subject because more and more women are joining the work force and having to cope with the demands of being a wage earner, wife and mother. There is growing concern that a woman's involvement in these multiple roles is detrimental to her physical and mental well-being.

In Ghana, women bear the extra stress of worrying about domestic factors - work and home conflict are associated with high stress in employed women and such stress takes its toll on a woman's physical and mental health. The stress of carrying out two full-time jobs (in the labor force and at home) is wearing many women out. Yet women by and large, are unprepared for the degree of conflict that arises between domestic and career responsibilities. The challenge therefore has been to find practical strategies informed by empirical research to sustain and support the managerial woman's work environment to achieve the intended organizational and individual outcomes within a competitive world of work. So far, the impact of work stress on women managers in Ghana has not been assessed systematically. Hence, considering the importance of the role of women in the development of our nation, a systematic investigation of work stress in managerial women's health is warranted in order to find appropriate organizational, 
societal and individual strategies to deal with the issues of concern. The objective of this study is to show the kind of work-related stressors that are unique to managerial women in Ghana and the link that these stressors have with anxiety, depression and physical symptoms by examining:

i. the specific sources of occupational stress experienced by managerial women in Ghana, and finding out which occupational stress facet has the greatest impact on managerial mental health,

ii. the effect of variables such as, maternal role, age and organization type on the health outcomes of the managerial women,

iii. the degree and level of occupational stress and the effects that these stressors have on the managerial women's psychological well-being.

\section{Theoretical framework}

There are numerous etiological models that have been offered to address the question of how and under what circumstances work stress may lead to strain. Many of these formulations are consistent with a generally accepted metamodel in stress research according to which the relationship between stress and strain is mediated, moderated or modified by individual difference variables. The stress response (i.e., strain) is viewed as the result of an interaction between person and environment. Applied to occupational stress, the specific components of this tripartite transactional model are the work environment, the person and strain. The work environment is where stressors are found. In particular, regarding occupational stress, this study examined the theoretical underpinnings of Person-Environment Fit Theory. According to the Person-Environment Fit (P-E Fit) Theory, job stress is defined as work attributes that pose threats or risks to an employee, resulting from a poor Person-Environment Fit, and strain is defined as the effects of stress on the individual, and various outcomes such as illness, psychiatric symptoms and propensity to leave the job emerge.

P-E Fit Theory of stress (Caplan, 1983; Caplan and Harrison, 1993) suggests that stress arises out of the fit or congruence between the person and the environment. The theory predicts that strain increases as the environment deviates from the person. This theory provides a framework for describing how the person and the environment combine to produce stress and influence strain, leading to adverse health outcomes. The basic idea of the P-E Fit model is that individual adjustment consists of goodness of fit between the characteristics of a person and the properties of that person's environment. A person's environment might include for example the work situation, the family arrangement and the social environment. In applying this theory in relation to gender, the focus is on the structural characteristics of the nature of the white collar job and the managerial role. The managerial role may enjoy some advanced skills and share some generous salaries and benefit packages, a high level of security and greater latitude of creative control over their tasks. Despite what may be viewed as extended freedom for the managerial role, every organization has its limits, boundaries and formalized systems of work and as far as women are concerned the boundaries may even be enormous. The environment that is most commonly the place of work of the woman manager (white collar job) is what makes the difference. The main sources of stress are directly connected with the task structure or the role and status of the woman manager within the organization. Such job conditions include: heavy workload, role ambiguity and conflict, job insecurity, poor relationships with co-workers, supervisors and work that is narrow, repetitive and monotonous; other factors include sexual harassment and family balance issues. Prejudice and discrimination may also be stressors for women in the workplace.

The specific stress which has been identified for managers and professionals, both males and females, in general include factors intrinsic to the job, role-based stress, relationships, career development factors, organizational structure and climate, and workfamily interface (Glowinkowski and Cooper, 1987). Quick and Quick (1984) through an all-embracing review of the medical, psychological, and managerial literature, also classify stressors faced by individuals in organizations as role demands, job demands, environmental demands, interpersonal demands and extra organizational demands. All these stressors can have a consequential impact on the mental health of the woman at the workplace.

A mentally healthy person, argues Kamau (1992), is one who is free from anxiety, and disability symptoms. If the individual can establish relationships with others and cope well with life's demands, then that individual's physical, mental, social and emotional well-being can be said to be complete. Kamau conceptualized mental health under five subscales as: personal wellbeing; anxiety factor; disability symptoms; capacity to establish constructive relationships; and the capacity to cope with the ordinary demands and stress of life. Thus, for the managerial women studied, good mental health is seen as essential for their ongoing professional growth as well as for creating a good emotional climate for an effective organization. This is because good mental health often has a bearing on making the right decisions and poor mental health may cause a manager to be ineffective. A woman manager with bad mental health not only tends to incapacitate herself for the performance of her many duties in the organization, but also creates difficulties and problems for her subordinates. Women managers by their nature engage in a wide variety of activities and must have the physical energy and mental health to stand the demands of such activities.

\section{Methodology}

\subsection{Data collection}

The target population for the study was managerial women. Participants for this study were a sample of women in managerial positions in Accra. Accra was chosen as the primary setting for this study due to its high concentration of major and key organizations and institutions which engage highly skilled women in Ghana, and also due to its cosmopolitan atmosphere. The ages of the women ranged from a minimum of 24 to a maximum of 58 years, with a mean age of 37.84 and a standard deviation of 7.66. The managerial women sampled were highly educated with either University degrees or with professional qualifications and had managerial responsibilities in their organizations and were mainly lower to upper level managers in their organizations. Forty (40) organizations which were likely to have managerial women on their staff list were identified. Out of the forty organizations, twenty-five (25) organizations which had substantial numbers of managerial women were also identified and randomly selected. The selected organizations fell into three major categories, namely Private, Public, and Multinational.

A self-report assessment questionnaire consisting of four different sections (i.e. Sections A-D) was used as the data collection tool. Section A consisted of questions on subjects' demography. Section B consisted of Occupational Stress measures, which are listed items in the stress subscales of the Occupational Stress Indicator (OSI) (Cooper et al., 1988), and its modified version, the Pressure Management Indicator (PMI) (Williams and Cooper, 1998). Section C consisted of mental health measures from the Depression, 
Anxiety and Stress Scale (DASS, Lovibond and Lovibond, 1995). Section D also consisted of measures of common physical symptoms of anxiety from the Beck's Anxiety Inventory (BAI) (Beck and Steers, 1990).

A total of 200 questionnaires were distributed and 175 were returned. Of the respondents $51(30 \%)$ were from private organizations, 59 (34.7\%) were from Public organizations, and 60 (35.3\%) were from multinational organizations. Of the 175 questionnaires returned, 170 were usable. This constitutes a response rate of $85 \%$ of respondents. Distributions of the marital status, educational levels and organization category of the 170 respondents whose questionnaires were used are shown in Figs. 1-3, respectively.

Fifteen (15) women who scored above and below the median on the sources of stress scale were selected for in-depth interviews. This method has been used successfully by Korabik et al. (1993) in their study on work stress and coping among managers. The interview sessions were aimed at supplementing the survey responses as well as obtaining information not directly elicited in the questionnaire. Respondents were also probed further about their responses on the survey. The investigator used the process of telephone calls and personal visits to the women's offices to fix appointments and administer or collect questionnaires. The data collection phase took approximately four (4) weeks.

\subsubsection{Measurement of occupational stress}

The Occupational Stress Indicator (OSI), which was modified and renamed the Pressure Management Indicator (PMI), was the instrument employed in measuring occupational stress. The OSI was developed by Cooper et al. (1988) as a tool to aid organizations in the diagnosis of psychosocial hazard related to stressful working conditions. The OSI is based on a model of occupational stress which identifies sources of pressure (experiences in the workplace) as causing stress effects (low job satisfaction, poor mental and physical health) which are moderated by individual differences (coping skills and stress prone personalities). But based on the argumentation by Williams and Cooper (1998) that the OSI entails some limitations, extra items were designed to strengthen its (i.e., OSI) weaker scales. Additional scales that are measures of organizational commitment, job security and decision latitude were also produced and added to the strengthened OSI measures to produce the Pressure Management Indicator (PMI) (Williams and Cooper, 1998; Rick et al., 2001). In this study, therefore, the occupational stress scale measure used is same in the OSI and the PMI. Thus, the OSI is still a popular instrument for the diagnosis of stress and stress-related personality and outcome variables. It is a frequently used set of scales to understand stress at work. The OSI consists of six subscales which tap six dimensions of stress:

i) Factors intrinsic to the job taps sources of stress originating from aspects of the job such as the amount and scope of tasks, number of hours worked and variety in the job.

ii) Managerial role measures how individuals perceive the expectations that others have of them. These expectations pertain to behaviours that managers are expected to exhibit when occupying their positions and performing routine job tasks.

iii) Relationship with others taps stress originating from personal contacts at work such as lack of social support from superiors and office politics.

iv) Career and achievement is concerned with respondents' perceptions of their career development, promotion prospects and perceived threats of job obsolescence.

v) Home-work interface measures stress originating from difficulties in coordinating family responsibilities with career demands. More specifically, this subscale measures whether non-work (home) stress has negative consequences on the individual's work and whether work demands have a negative impact on home life.

vi) Organizational structure and climate measures stress originating from the bureaucratic nature of the organization, communication problems and morale in the organizations.

The following 28 items on the stress subscale measures in the OSI were appraised: work overload; ambiguity about your responsibilities; feeling isolated; covert discrimination and

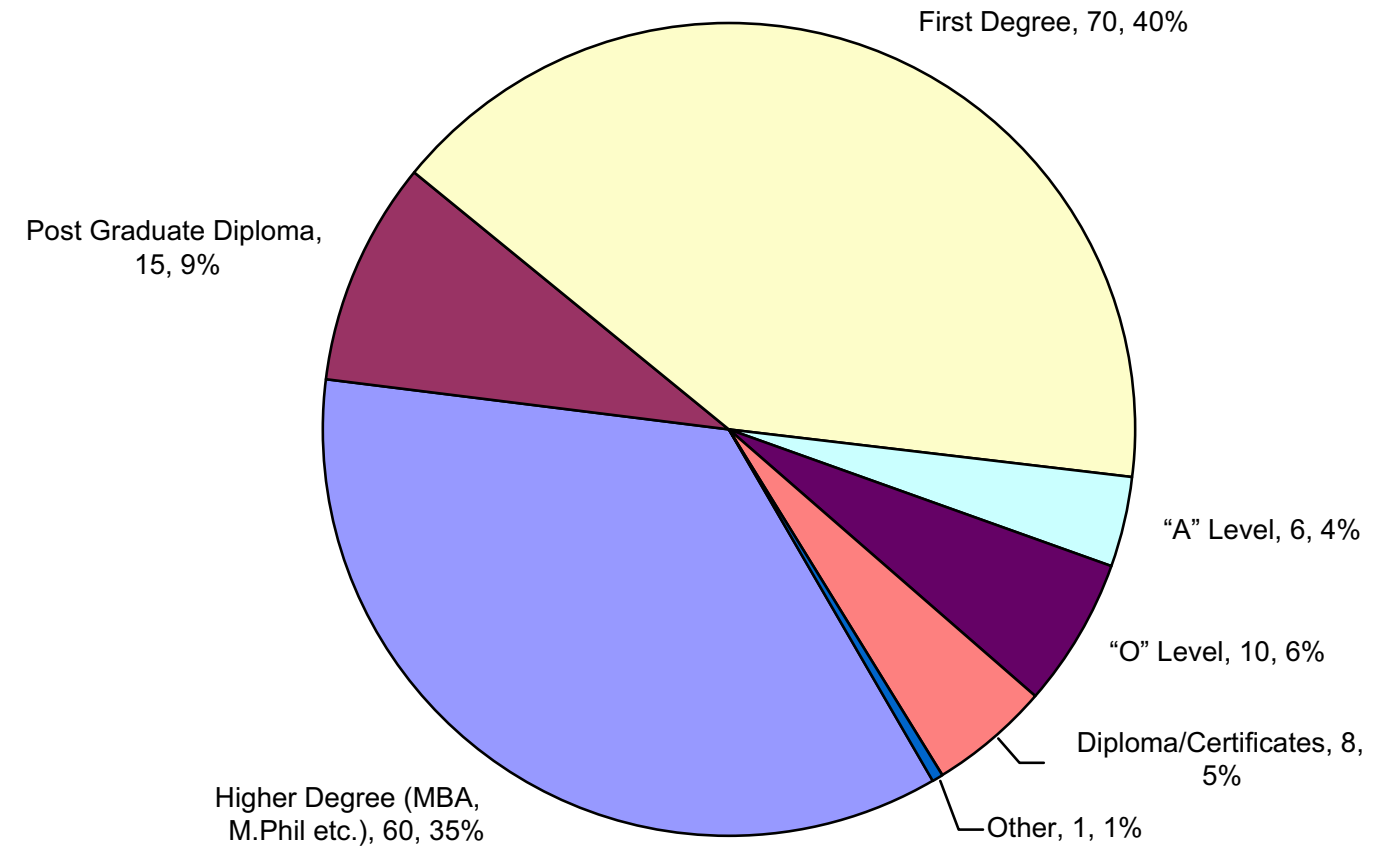

Fig. 1. Summary of demographic data on respondents' educational levels. 


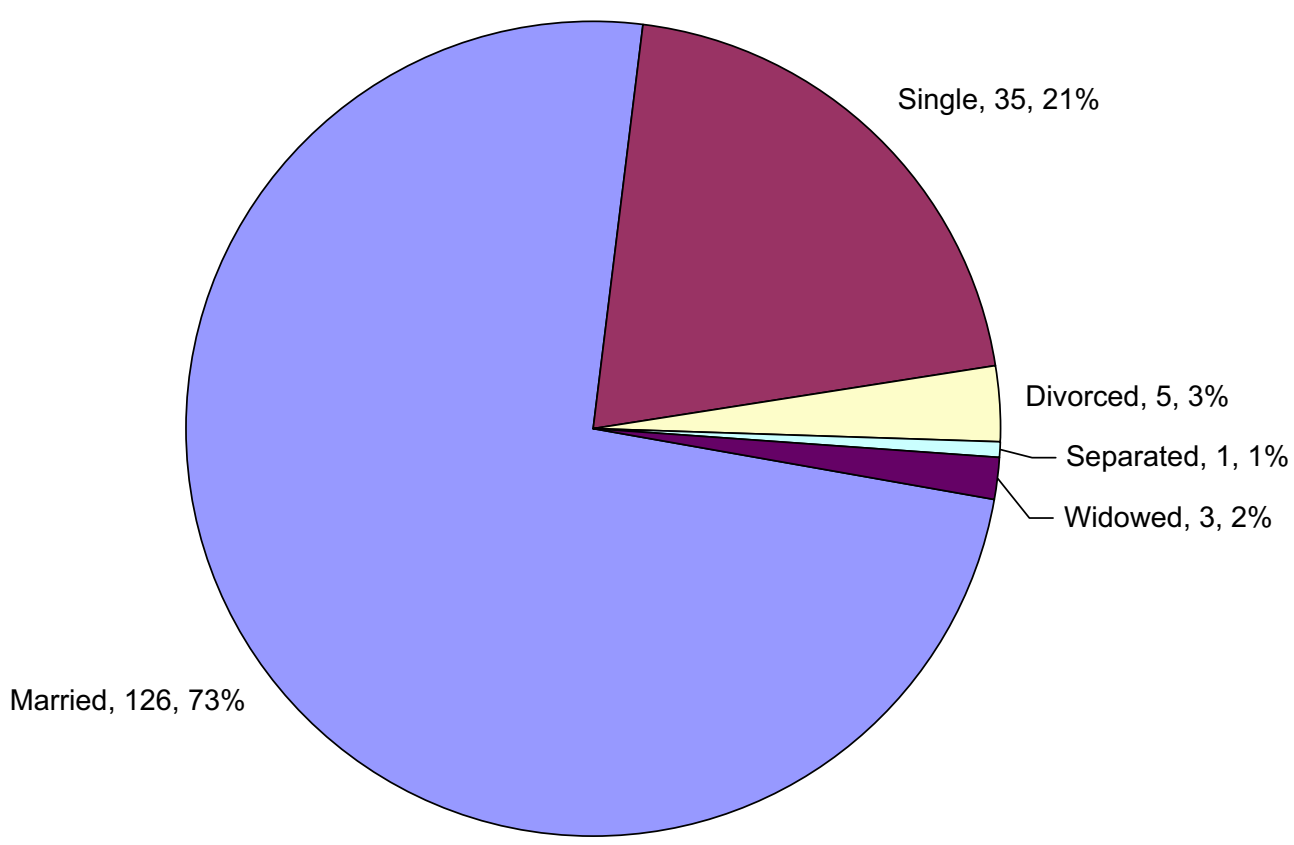

Fig. 2. Summary of demographic data on respondents' marital status.

favoritism; pursuing a career at the expense of home life; rates of pay; keeping up with new techniques; too little variety in work; time pressures and deadlines; coping with office politics; job insecurity; lack of opportunities for further development; inadequate feedback about my performance; insufficient resources and finance to work with; staff shortages and turnover rates; lack of control in my work environment; long working hours; feeling undervalued; attending meetings; poor interpersonal; relationships at work; conflict between work and home/social life; managing/supervising people; insufficient control over your job; under-promotion; no or little participation in decision making; too much responsibility; over-promotion (promoted beyond my competence); and too little responsibility.

These items were scored from 1 (very definitely is not a source of stress) to 7 (very definitely is a source of stress). The OSI has a score range of 28-196. The median split method was used in categorizing the stress scale into high and low levels. The high score ranges from 112 to 196 and low score ranges from 28 to 111 (Broadbridge, 2000; Cooper et al., 1988). High scores indicate more pressure faced by the individual. The study measured sources of

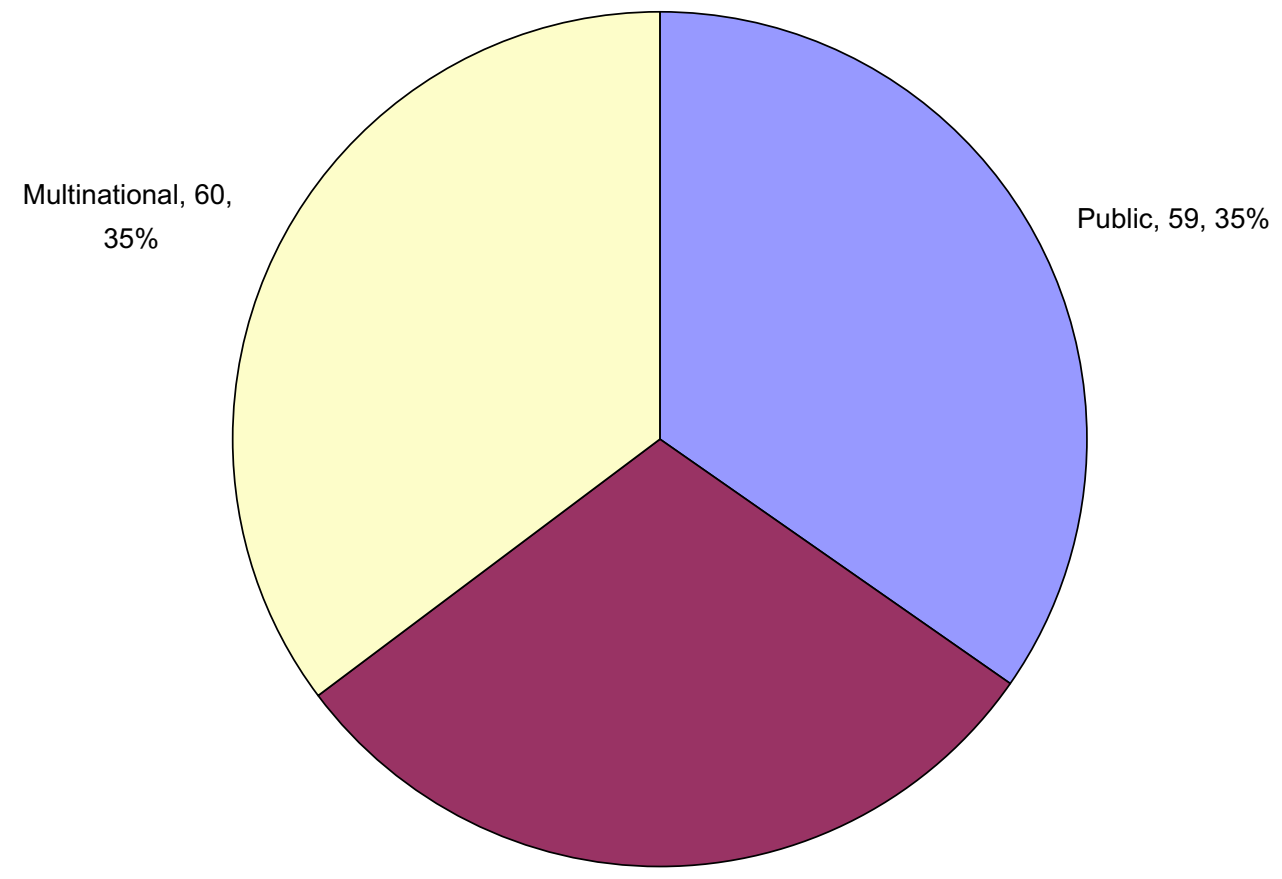

Private, $51,30 \%$

Fig. 3. Summary of demographic data on respondents' organization category. 
stress which were assessed with 28 items adopted from the OSI. The subscale reliability as reported by Williams and Cooper (1998) showed subscale coefficient alphas as follows: Factors intrinsic to the job $(\alpha=0.70)$; Managerial role $(\alpha=0.80)$; Relationships with other people $(\alpha=0.78)$; Career and achievement $(\alpha=0.78)$; Organizational structure and climate $(\alpha=0.83)$; and Home-work interface $(\alpha=0.84)$. Factor loadings for the scale showed particularly strong validity in the range of $0.58-0.70$. For the whole scale, the reliability coefficient for the present study was Cronbach's alpha $(\alpha)$ of $0.91(M=4.34$; SD 1.60). The subscales were: Factors intrinsic to the job $(\alpha=0.71)$; Managerial role $(\alpha=0.79)$; Relationships with other people $(\alpha=0.77)$; Career and achievement $(\alpha=0.76)$; Organizational structure and climate $(\alpha=0.81)$; and Home-work interface $(\alpha=0.80)$.

\subsubsection{Measurement of mental health}

The Depression, Anxiety and Stress Scale (DASS) is a 42-item instrument measuring current ("over the past week") symptoms of depression, anxiety and stress. The DASS was specifically designed to distinguish between, and provide relatively pure measures of the three related and clinically significant negative emotional states of depression, anxiety and stress. It provides a quantitative (dimensional) measure of the severity of each syndrome. The psychometric properties of the DASS have been demonstrated to be good in numerous studies. Lovibond and Lovibond (1995) report Gamma coefficients of 0.71 for depression, and 0.86 for anxiety. Reliability of the scales is considered adequate and test-retest reliability is likewise considered adequate with 0.71 for depression, and 0.79 for anxiety. Brown et al. (1997) also report that exploratory and confirmatory factor analyses have sustained the proposition of the three factors in the predicted direction $(p<0.05)$. Factor analytic studies have confirmed that the DASS items can be reliably grouped into three scales, namely Depression, Anxiety, and Stress, in both non-clinical (Lovibond and Lovibond, 1995) and clinical samples (Brown et al., 1997). Support for criterion validity was provided by a statistically significant difference in DASS scores between two diagnostic groups. A cut-off score of 5 for anxiety and 12 for depression is recommended (Nieuwenhuijsen et al., 1995). The DASS, therefore, reflects contemporary thinking on the nature of negative emotions and has well-established psychometric properties. It also provides a measure of tension/stress as well as depression and anxiety. Moreover, the DASS is extensively used world wide particularly in Australia and other parts of the world in research studies, clinical assessment and outcome evaluation. It is therefore an instrument that would be valuable for use with client population from different cultural backgrounds.

The depression and anxiety section of the DASS 42-item was used for this study. Each of the two scales contains 14 items, a high score is indicative of lower mental health. Participants were asked to use a 5-point combined severity/frequency scale to rate the extent to which they have experienced each item over the past three months. This adjustment of time duration from 'over the past week' to 'over the past three months' was deemed necessary based on the responses that emerged from the pilot study. Respondents indicated that the time duration was too short. The reliability

Table 1

Severity-rating index

\begin{tabular}{llc}
\hline & Depression & Anxiety \\
\hline Normal & $0-9$ & $0-7$ \\
Mild & $10-13$ & $8-9$ \\
Moderate & $14-20$ & $10-14$ \\
Severe & $21-27$ & $15-19$ \\
Extremely severe & $28+$ & $20+$ \\
\hline
\end{tabular}

coefficients for this study were: Anxiety, Cronbach's alpha $(\alpha)=0.88,(M=0.50 ; \mathrm{SD}=0.79)$ and Depression Cronbach's alpha $(\alpha)$ of $0.90,(M=0.55 ; \mathrm{SD}=0.79)$. The DASS scale ranges from 0 (did not apply to me at all) to 4 (applied to me severely, or all the time). Scores for Depression and Anxiety are calculated by summing the scores for the relevant items. A sum of the scores for each of the 14 questions completed by each participant in each of the sub-scales is evaluated as per the severity-rating index shown in Table 1.

\subsubsection{Measurement of common physical symptoms of anxiety}

The Beck's Anxiety Inventory (BAI) (Beck and Steers, 1990) was used. It is a 21-item self-report measure of common physical symptoms of anxiety. The items ask how much the person has been bothered by symptoms in the past week on a four-point Likert scale. Higher scores indicate higher anxiety. There is considerable supportive evidence for the reliability and validity of the BAI, for example, Lovibond and Lovibond (1995) in a study reported that the DASS anxiety scale correlates 0.81 with the Beck Anxiety Inventory (BAI). Factor loadings for the scale is 0.86 providing good validity for the scale. Respondents were given the following instructions: "Below is a list of some common symptoms. Please read each item in the list carefully and indicate how much you have experienced each symptom during the past three months, including today. Then mark the box that corresponds to the response appropriate to you." Responses were from 0 (not at all), (1) Mildly: It did not bother me much; (2) Moderately: it was very unpleasant but I could stand it; to (3) Severe: I could barely stand it. The reliability coefficients in this study were Cronbach's alpha $(\alpha)$ of 0.93 , $(M=0.48 ; \mathrm{SD}=0.74)$.

\subsection{Results analysis}

The primary goal of this study was to identify the common stressors that are unique to women managers in Ghana, and the debilitating effects of these stressors on their psychological wellbeing. Therefore the unit of analysis was the female managerial woman in Ghana. The data analyzes were conducted in two steps. In the first instance, the means, standard deviations, correlations and internal consistency estimates (Cronbach's alpha) were computed for each of the variables. Table 2 presents the means, standard deviations, and correlational matrix for the variables employed in analyzing the relationship between occupational stress and mental health.

The correlation results indicated that mental health was significantly related to stress: $r_{(170)}=0.25, p<0.01$; This result indicated that the more stressors the women reported as experiencing, the more likely they will report mental ill-health. The result also revealed that individual mental health indices showed a significant relationship with stress: anxiety, $r\left({ }_{170}\right)=0.24, p<0.01$; depression, $r(170)=0.28, \quad p<0.01$; and physical symptoms, $r(170)=0.17$, $p<0.05$.

Since the relationships between work stress and mental health may be affected by managerial women's socioeconomic status and other background factors, correlations between the stressor and mental health scale indices and respondents' socio-demographic characteristics were also calculated. Table 2 indicated that out of these variables only level of education was significantly related to mental health $\left(r_{(170)}=0.18, p<0.01\right)$. Other variables like age $r_{(170)}=-0.12$, marital status $r_{(170)}=0.08$, organizational tenure $r_{(170)}=0.03$, and managerial tenure, $r_{(170)}=-0.04$, were not significantly related to mental health. However, the causal interpretation of this correlational data must be viewed with caution, for the reason that age and educational characteristics have been found in other studies to confound the stress illness relationship (e.g., Lim and Thompson, 1996; Manning et al., 1996; Wells, 1982). There was 


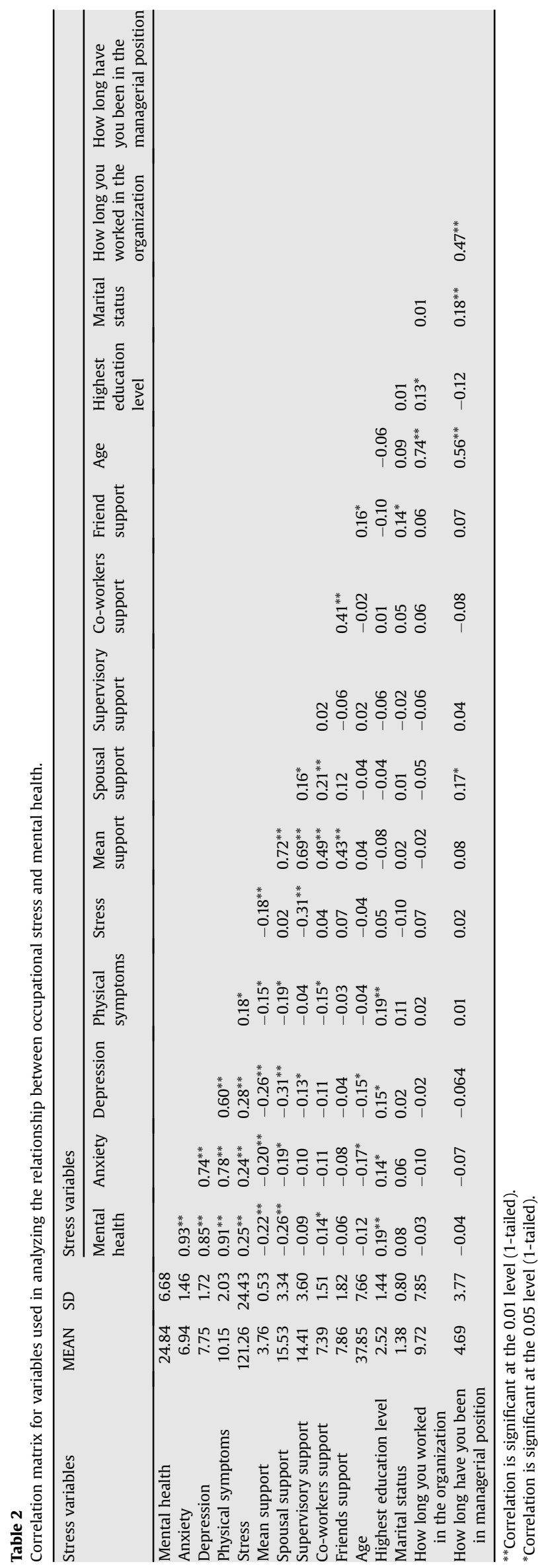

Table 3

Hierarchical multiple regression analysis of mental health on stress and control variables.

\begin{tabular}{lllll}
\hline Variables & $R$-square & $\begin{array}{l}\text { Changed } \\
R \text {-square }\end{array}$ & $\begin{array}{l}\text { Standardized } \\
\text { beta }(\beta)\end{array}$ & $F$ \\
\hline Control variables & $0.05^{*}$ & $0.05^{*}$ & -0.12 & $3.11^{*}$ \\
$\begin{array}{l}\text { Age } \\
\text { Type of organization }\end{array}$ & & -0.08 & \\
Education & & & 0.18 & $5.13^{* *}$ \\
All variables & $0.13^{* *}$ & $0.08^{* *}$ & & \\
Age & & & -0.11 & \\
Type of organization & & & -0.07 & \\
Education & & & 0.16 & \\
Stress & & & & \\
${ }^{*} p<0.05,{ }^{* * *} p<0.01$. & & & &
\end{tabular}

therefore the need to control for these variables which are not of interest in the current study. This is to ensure that any significant relationship found in experienced stress and mental health is attributed to the variables of interest. Since educational characteristics were also related to the work stress mental health relationship in this study, their 'effects' together with age and type of organization (Cooper and Marshall, 1978) were removed by controlling for them in all the subsequent analysis, where a series of hierarchical multiple regression analysis were conducted.

In order to test the hypotheses that higher levels of reported job stress will lead to greater mental health problems among managerial women, the composite mental health index was regressed on the composite stressor index, and control variables using the hierarchical multiple regression analysis (Enter method). The results are shown in Table 3 above.

From Table 3 below, the hierarchical multiple regression analysis (Enter method) indicated that a significant model emerged $\left(F_{(5.164)}=5.13, p<0.01\right)$. The $R$-square was 0.13 indicating that the model as a whole explained thirteen percent (13\%) of the variance with stress explaining the additional $8 \%$ (changed $R^{2}=0.08$ ) of the variance when age, type of organization and education were statistically controlled. Though small (changed $R^{2}=0.08$ ), the contribution of stress was statistically significant, $\left(F_{(2,165)}=7.789\right.$, $p<0.01)$. The contribution of stress to the model indicated that stress was significantly positively related to mental health $(\beta=0.21$, $p<0.01$ ), thus stress was a significant predictor of mental health when age, type of organization and education were controlled. However, the strength of the relationship was small (Cohen, 1988). The interrelations reported between stress and mental health while statistically significant is not very strong in an absolute sense. Several factors placed an expected upper limit on the strength of these relationships. Firstly, the study attempted to minimize the conceptual overlap between measures by choosing to relate a measure of the work environment to indices of the managerial woman's overall health status (such as depression anxiety and physical symptoms) rather than to measures of work strain (such as job dissatisfaction boredom, frustration). Since general health has multiple determinants, one would expect the work environment to account for only a limited amount of the variance in mental health. In this respect, therefore, the hypothesis that the stressors in the Ghanaian women managers' job environment are in actual fact predicting mental health symptoms (depression, anxiety and physical symptoms) was supported.

The study further used hierarchical multiple regression analysis to examine the hypothesis that managerial women with children will exhibit lower mental health than women without children. In order to test this hypothesis the composite mental health index was regressed on maternal role, while controlling for number of children and age of children (Beatty, 1996). The results are depicted in Table 4 below. 
Table 4

Hierarchical multiple regression analysis of mental health on maternal role, and control variables (number and age of children).

\begin{tabular}{lllll}
\hline & $R$-square & $\begin{array}{l}\text { Changed } \\
R \text {-square }\end{array}$ & $\begin{array}{l}\text { Standardized } \\
\text { beta }\end{array}$ & $F$ \\
\hline Control variables & 0.07 & 0.07 & -0.18 & 2.31 \\
Age & & & $0.24^{*}$ & \\
$\begin{array}{l}\text { Education } \\
\text { Number of children }\end{array}$ & & 0.18 & \\
School age of children & & & 0.04 & $5.48^{* *}$ \\
All variables & $0.19^{* *}$ & $0.12^{* *}$ & & \\
Age & & & -0.16 & \\
Education & & & $0.26^{* *}$ & \\
Number of children & & & $0.27^{* *}$ & \\
School age of children & & & $-0.36^{* *}$ & \\
Maternal role & & &
\end{tabular}

${ }^{*} p<0.05,{ }^{* *} p<0.01$

From Table 4 below, it can be observed that a significant model emerged $\left(F_{(5,113)}=5.48, p<0.01\right)$ when the hierarchical multiple regression analysis (Enter method) was conducted. The $R$-square was 0.19 indicating that the model as a whole explained $19 \%$ of the total variance with the additional $12 \%$ (changed $R^{2}=0.12$ ) being explained by maternal role, when age, education, number of children and school age of children were statistically controlled. Thus change $\left(R^{2}\right.$ change) was statistically significant, $\left(F_{(1,113)}=16.86\right.$, $p<0.01$ ) when maternal role was introduced into the model. Maternal role was significantly negatively related to mental health that is managerial women with children exhibited lower mental health than those without children who exhibited higher mental health.

One-way MANOVA was used to examine whether or not any such differences existed in the response patterns of the women managers among the different organizations represented in the study. This is based on the assumption that the type of organization implies basic differences in policies, structures and organizational cultures (Cooper and Marshall, 1978). These may result in differences in the organization's support for gender-related issues, for example, childcare problems (Freedman, 1990). The results of the one-way MANOVA are shown in Table 5 below.

The main effect of organization type on mental health was not significant in that no significant differences existed among the three organizations: private $(M=24.10)$, public $(M=28.97)$ and multinational $(M=21.42),\left(F_{(2,167)}=1.87, p=n s\right)$. Similarly, the main effect of organization type on stress did not reach significance. No significant differences in stress levels were reported among private $(M=122.55)$, public $(M=118.86)$ and multi-national $(M=122.53),\left(F_{(2,167)}=0.43, p=n s\right)$. Each of the stress factors was individually examined to find their relationships to mental health. The results of the hierarchical multiple regression analysis (see Table 6) indicate that only five factors (Feeling undervalued, Inadequate feedback about my performance, Insufficient resources and

Table 5

Result of the one-way MANOVA test on the stress and mental health.

\begin{tabular}{llrlrrr}
\hline Source & $\begin{array}{l}\text { Dependent } \\
\text { variable }\end{array}$ & \multicolumn{1}{c}{$\begin{array}{l}\text { Sum of } \\
\text { squares }\end{array}$} & $\begin{array}{l}\text { Mean } \\
\text { square }\end{array}$ & df & $F$ & Sig. \\
\hline $\begin{array}{l}\text { Organization } \\
\text { type }\end{array}$ & Mental health & 1735.697 & 867.843 & 2 & 1.866 & 0.158 \\
Error & Stress & 520.612 & 260.306 & 2 & 0.433 & 0.649 \\
& Mental health & $77,667.025$ & 465.072 & 167 & & \\
\multirow{2}{*}{ Total } & Stress & $1,00,334.476$ & 600.805 & 167 & & \\
& Mental health & $79,402.712$ & & 169 & & \\
& Stress & $1,00,855.088$ & & 169 & & \\
\hline
\end{tabular}

${ }^{*} p<0.05,{ }^{* *} p<0.01$ finance to work with, Staff shortages and turnover rates, and Too much responsibility) remained statistically significant after controlling for age, educational level and type of organization.

As can be seen from Table 7, individually the same stress factor that predicted depression did not simultaneously predict anxiety and physical symptoms. For example, "feeling isolated" predicted depression, but did not predict anxiety and physical symptoms; whereas keeping up with new techniques predicted both depression and anxiety, but did not predict physical symptoms. However, only one stress factor, "insufficient resources and finance to work with", seemed to have predicted all three indices of mental health (depression, anxiety and physical symptoms).

As a follow up to the quantitative data and to further augment the data as a whole, a series of interview sessions were held with a random cross-section of the women who scored high and low on the sources of stress scale as suggested by Lim and Thompson

Table 6

Hierarchical multiple regression analysis of individual stressors on mental health (note: dependent variable is mental health).

\begin{tabular}{|c|c|c|c|c|}
\hline & $R$-square & $\begin{array}{l}R \text {-square } \\
\text { changed }\end{array}$ & $\begin{array}{l}\text { Standardized } \\
\text { beta }\end{array}$ & $p$ \\
\hline Control variable & 0.05 & 0.05 & & 0.04 \\
\hline 1. Age & & & & 0.113 \\
\hline 2. Type of organization & & & -0.124 & 0.319 \\
\hline $\begin{array}{l}\text { 3. Highest educational level } \\
\text { attained }\end{array}$ & & & -0.077 & 0.030 \\
\hline All variables & 0.39 & 0.34 & 0.168 & 0.01 \\
\hline 1. Age & & & -0.018 & 0.819 \\
\hline 2. Type of organization & & & -0.066 & 0.396 \\
\hline $\begin{array}{l}\text { 3. Highest educational level } \\
\text { attained }\end{array}$ & & & 0.107 & 0.164 \\
\hline 4. Work overload & & & -0.036 & 0.723 \\
\hline $\begin{array}{l}\text { 5. Ambiguity about your } \\
\text { responsibilities }\end{array}$ & & & 0.110 & 0.222 \\
\hline 6. Feeling isolated & & & 0.190 & 0.048 \\
\hline $\begin{array}{l}\text { 7. Covert discrimination and } \\
\text { favoritism }\end{array}$ & & & 0.059 & 0.582 \\
\hline $\begin{array}{l}\text { 8. Pursuing a career at the expense } \\
\text { of home life }\end{array}$ & & & 0.023 & 0.819 \\
\hline 9. Rates of pay & & & 0.012 & 0.903 \\
\hline 10. Keeping up with new techniques & & & 0.160 & 0.056 \\
\hline 11. Too little variety in work & & & -0.180 & 0.061 \\
\hline 12. Time pressures and deadlines & & & -0.136 & 0.200 \\
\hline 13. Coping with office politics & & & 0.081 & 0.423 \\
\hline $\begin{array}{l}\text { 14. Lack of opportunities for further } \\
\text { development }\end{array}$ & & & -0.104 & 0.293 \\
\hline $\begin{array}{l}\text { 15. Inadequate feedback about my } \\
\text { performance }\end{array}$ & & & -0.304 & 0.005 \\
\hline $\begin{array}{l}\text { 16. Insufficient resources and finance } \\
\text { to work with }\end{array}$ & & & 0.302 & 0.007 \\
\hline 17. Job insecurity & & & 0.168 & 0.136 \\
\hline 18. Staff shortages and turnover rates & & & -0.216 & 0.021 \\
\hline $\begin{array}{l}\text { 19. Lack of control in my work } \\
\text { environment }\end{array}$ & & & -0.131 & 0.217 \\
\hline 20. Long working hours & & & 0.140 & 0.176 \\
\hline 21. Feeling undervalued & & & 0.187 & 0.075 \\
\hline 22. Attending meetings & & & 0.062 & 0.490 \\
\hline $\begin{array}{l}\text { 23. Poor interpersonal relationships } \\
\text { at work }\end{array}$ & & & -0.011 & 0.905 \\
\hline $\begin{array}{l}\text { 24. Conflict between work and } \\
\text { home/social life }\end{array}$ & & & 0.069 & 0.467 \\
\hline 25. Managing/supervising people & & & 0.043 & 0.646 \\
\hline 26. Insufficient control over your job & & & 0.020 & 0.856 \\
\hline 27. Under-promotion & & & -0.116 & 0.283 \\
\hline $\begin{array}{l}\text { 28. No or little participation in } \\
\text { decision making }\end{array}$ & & & -0.116 & 0.205 \\
\hline 29. Too much responsibility & & & 0.203 & 0.029 \\
\hline $\begin{array}{l}\text { 30. Over-promotion (promoted } \\
\text { beyond my competence }\end{array}$ & & & 0.190 & 0.063 \\
\hline 31. Too little responsibility & & & -0.161 & 0.124 \\
\hline
\end{tabular}

${ }^{*} p<0.05 ;{ }^{* *} p<0.01$ 
Table 7

Individual stress factors and indices of mental health.

\begin{tabular}{|c|c|c|c|c|c|c|}
\hline \multirow[t]{2}{*}{ Individual stress factors } & \multicolumn{2}{|c|}{ Depression } & \multicolumn{2}{|l|}{ Anxiety } & \multicolumn{2}{|c|}{ Physical symptoms } \\
\hline & Beta & Sig. & Beta & Sig. & Beta & Sig. \\
\hline Ambiguity about my responsibilities & 0.066 & 0.477 & 0.014 & 0.151 & 0.180 & 0.049 \\
\hline Feeling isolated & 0.250 & 0.012 & 0.169 & 0.079 & 0.113 & 0.242 \\
\hline Too little variety in work & -0.110 & 0.266 & -0.159 & 0.100 & -0.201 & 0.039 \\
\hline Keeping up with new techniques & 0.186 & 0.032 & 0.175 & 0.038 & 0.090 & 0.284 \\
\hline Inadequate feedback about my performance & -0.147 & 0.184 & -0.228 & 0.035 & -0.393 & 0.000 \\
\hline Insufficient resources/finance to work with & 0.251 & 0.031 & 0.222 & 0.049 & 0.318 & 0.005 \\
\hline Lack of control in my work environment & -0.220 & 0.047 & -0.167 & 0.120 & -0.010 & 0.923 \\
\hline Staff shortages and turnover rates & -0.128 & 0.186 & -0.252 & 0.008 & -0.201 & 0.034 \\
\hline Feeling undervalued & - & - & - & - & 0.215 & 0.044 \\
\hline Too much Responsibility & 0.195 & 0.043 & 0.231 & 0.014 & 0.139 & 0.139 \\
\hline Over-promotion & 0.045 & 0.671 & 0.250 & 0.016 & 0.206 & 0.046 \\
\hline No or little participation in decision making & -0.028 & 0.765 & -0.493 & 0.623 & -0.199 & 0.032 \\
\hline
\end{tabular}

${ }^{*} p<0.05^{* *} p<0.01$.

(1996) and Korabik et al. (1993). The demographic characteristics of the women indicate that the two groups of women (those high and low on stress) are similar in marital status, number of children, and school age of children. However, in terms of age, the women in the low stress group differ slightly in mean age indicating that those in the low stress group are proportionately older than those in the high stress group. In terms of educational level, the low stress group also has proportionately higher educational qualifications than those in high stress group. This is consistent with those of the quantitative results of this study, which showed that age and educational levels were significant predictors of stress and mental health.

The quantitative data (as highlighted in Table 8 below) revealed that the women reported significantly higher scores on eighteen (18) items on the sources of stress scale as factors that contributed significantly to their stress. These items are as follows: (i) work overload; (ii) ambiguity about your responsibilities; (iii) pursuing a career at the expense of home life; (iv) rates of pay; (v) keeping up with new techniques; (vi) time pressures and deadlines; (vii) coping with office politics; (viii) lack of opportunities for further development; (ix) inadequate feedback about my performance; $(x)$ insufficient resources and finance to work with; (xi) staff shortages and turnover rates; (xii) long working hours; (xiii) feeling undervalued; (xiv) conflict between work and home/ social life; (xv) under-promotion; (xvi) No or little participation in decision making; (xvii) too much responsibility; and (xviii) overpromotion (promoted beyond my competence).

It was also revealed that out of these items, five (5) among the stressors tended to have the greatest impact on their mental health (refer to Table 6 above). These are (i) feeling isolated, (ii) inadequate feedback about my performance, (iii) insufficient resources and finance to work with, (iv) staff shortages and turnover rates, and (v) too much responsibility. Based on these results, questions were formulated which formed the basis of the interview session. A total

Table 8

One-sample $t$-test on individual stressors contribution to stress.

\begin{tabular}{|c|c|c|c|c|c|}
\hline \multirow[t]{2}{*}{ Variable } & \multirow[t]{2}{*}{ Mean } & \multirow[t]{2}{*}{ SD } & \multicolumn{3}{|c|}{ Test value $=4$} \\
\hline & & & $t$ & df & $p$ \\
\hline 1. Work overload & 4.6941 & 1.76436 & 5.129 & 169 & 0.000 \\
\hline 2. Ambiguity about your responsibilities & 4.3882 & 1.73781 & 2.913 & 169 & 0.004 \\
\hline 3. Feeling isolated & 4.0059 & 1.63720 & 0.047 & 169 & 0.963 \\
\hline 4. Covert discrimination and favoritism & 4.1471 & 1.65219 & 1.161 & 169 & 0.247 \\
\hline 5. Pursuing a career at the expense of home life & 4.4000 & 1.60399 & 3.251 & 169 & 0.001 \\
\hline 6. Rates of pay & 4.6529 & 1.67566 & 5.081 & 169 & 0.000 \\
\hline 7. Keeping up with new techniques & 3.6805 & 1.64886 & -2.519 & 168 & 0.013 \\
\hline 8. Too little variety in work & 3.8353 & 1.54113 & -1.393 & 169 & 0.165 \\
\hline 9. Time pressures and deadlines & 5.0059 & 1.58953 & 8.251 & 169 & 0.000 \\
\hline 10. Coping with office politics & 4.5647 & 1.54573 & 4.763 & 169 & 0.000 \\
\hline 11. Job insecurity & 4.2647 & 1.79263 & 1.925 & 169 & 0.056 \\
\hline 12. Lack of opportunities for further development & 4.6176 & 1.66436 & 4.839 & 169 & 0.000 \\
\hline 13. Inadequate feedback about my performance & 4.4647 & 1.62504 & 3.729 & 169 & 0.000 \\
\hline 14. Insufficient resources and finance to work with & 4.7381 & 1.71725 & 5.571 & 167 & 0.000 \\
\hline 15. Staff shortages and turnover rates & 4.3353 & 1.57249 & 2.780 & 169 & 0.006 \\
\hline 16. Lack of control in my work environment & 4.1294 & 1.47795 & 1.142 & 169 & 0.255 \\
\hline 17. Long working hours & 4.7471 & 1.73738 & 5.606 & 169 & 0.000 \\
\hline 18. Feeling undervalued & 4.6235 & 1.64246 & 4.950 & 169 & 0.000 \\
\hline 19. Attending meetings & 4.1006 & 1.53392 & 0.853 & 168 & 0.395 \\
\hline 20. Poor interpersonal relationships at work & 4.2235 & 1.50641 & 1.935 & 169 & 0.055 \\
\hline 21. Conflict between work and home/social life & 4.4882 & 1.62538 & 3.916 & 169 & 0.000 \\
\hline 22. Managing/supervising people & 4.1941 & 1.42794 & 1.772 & 169 & 0.078 \\
\hline 23. Insufficient control over your job & 4.1588 & 1.45690 & 1.421 & 169 & 0.157 \\
\hline 24. Under-promotion & 4.5706 & 1.55311 & 4.790 & 169 & 0.000 \\
\hline 25. No or little participation in decision making & 4.4353 & 1.53420 & 3.699 & 169 & 0.000 \\
\hline 26. Too much responsibility & 4.4588 & 1.54654 & 3.868 & 169 & 0.000 \\
\hline 27. Over-promotion (promoted beyond my competence) & 3.6471 & 1.61872 & -2.843 & 169 & 0.005 \\
\hline 28. Too little responsibility & 3.7941 & 1.57607 & -1.703 & 169 & 0.090 \\
\hline
\end{tabular}

${ }^{*} p<0.05 ;{ }^{* *} p<0.01$. 
of 15 women were interviewed from the public, private and multinational organizations. A twelve-item open-ended interview schedule was used. The results from these interviews are presented below in the form of summaries. This approach to qualitative data analysis is related to the hermeneutic methodology advocated by Gabriel (1990). The interview findings are consistent with the quantitative data obtained and presented earlier, where no significant differences existed in the response patterns of the women among the different organizational types represented in the study. An analysis of the verbatim transcripts of the sampled interviewees provides the following perceptual views.

\section{Feeling isolated}

Eight of the women indicated that they worked in interdependent teams and their jobs basically involved interacting with people; they do enjoy this interaction very much and never felt isolated. Six women also indicated that they worked in relatively autonomous service oriented jobs and also enjoyed interacting with people. One woman however, reported feeling isolated when her team members were assigned to do projects individually.

Too little variety in work

Twelve of the women reported that the administrative procedures of their work schedules were quite repetitive. Only three indicated that their schedule gave them some form of initiative to vary the processes.

Keeping up with new technologies

Nine of the women interviewed commented that they were anxious that they may lag behind technologically; therefore they spent a lot of their free times reading and updating their skills so that they could keep themselves abreast with changing times. Six women, however, indicated that within their job environment, they really must know their jobs as women managers, so they could stay on top and at par with their male colleagues; therefore they always worked extra and hardly had any time for themselves.

\section{Additional responsibilities due to high turnover rates}

Eleven of the women reported that because people tended to leave very often in their organizations, management always expected them to hold themselves in readiness to take up more responsibilities. As a result they were supposed to do more within the same time frame which tended to make them anxious and felt that management had taken them for granted. Four women however indicated that though this happened quite often, it did not really bother them because it was temporary.

\section{Too much responsibility}

The women were concerned about making mistakes on their jobs and tended to get very anxious in taking over much responsibility. They indicated that they had to make sure that they gave the right impression to male colleagues and superiors. They also revealed that they could not afford to make mistakes on their jobs. As women in their organizations, they had to make sure that their performances did not fall short of others' expectations of them.

Feeling undervalued

Six of the women indicated that since there was no career development plan for them, they felt that their employers did not have their interest at heart which made them felt unappreciated. They also indicated that they felt so undervalued to the point that sometimes they asked themselves "why are we here"? Nine women however indicated that to some extent they felt appreciated.

\section{Over-promotion}

Nine of the women reported that they felt very apprehensive that they had not been given enough in-service training to handle all the additional duties they were currently responsible for. Six women, however, indicated that they believed they had the competencies to perform their duties.

Lack of resources and finance to work with

Thirteen women indicated that they needed to plan their activities based on budget, but then there was always a cut and shortage in resources, so they could not perform to the best of their abilities and were not able to meet their targets. They reported fund holding as a major barrier to accomplish duties satisfactorily. Two women, however, indicated that they used whatever was made available to them. Overall, the women managers in responding to the interview questions, reported deadline, time pressures, workload and meeting targets as factors that contribute significantly to stress and believed that these and other factors discussed above were responsible for certain psychological disorders and ailments they experienced often in their lives. These results are very consistent with the quantitative results presented earlier.

The common theme that runs through the interview session is the women's reported experience of stress and how these stressors impacted negatively on their mental health. These results are consistent with the quantitative data analyzed earlier.

\section{Discussion}

Building on other research findings, this study provided further evidence that self-reported stressors such as work overload, time pressure and deadlines, conflict and responsibility are significantly related to psychological strains in this population of managerial women. Theoretically, as these stressors increase, they exceed the capacities of the individual, increasing the likelihood of eliciting a broad array of psychological and psychosomatic symptoms (Lazarus and Folkman, 1984; Quick et al., 1997). Women may perceive various job conditions as stressful and in some cases depression becomes the female response and therefore these stressors tend to manifest themselves more readily in emotional outcomes such as anxiety and depression, rather than in the physiological responses most often noted in men. Those managerial women, who reported higher pressures, were significantly more likely to experience symptoms of depression, anxiety and somatic complaints. These results are consistent with findings in numerous studies in working managerial women (e.g., Davidson et al., 1995; Pisarski et al., 1998). Several researchers have found a link between stress and mental health. Snow et al. (2003) found in their study that the degree of job distress was found to be the best predictor of degree of depression, anxiety and physical symptoms. They reported a strong relationship between stress and health outcomes among female workers. In addition, Ganster and Schaubroeck's (1991) review of work stress and employee health concludes that strong evidence exists that stress causes illness. Cooper and Melhuish (1984) also in surveying 311 Senior Male managers and 171 Senior Female Managers reported that female managers tended to show their stress manifestations through mental ill-health. Again Davidson et al. (1995) in investigating the levels of occupational stress in 126 female graduates also reported substantial adverse illhealth outcomes of stress for female managers, especially in 
relation to mental and physical ill-health. A similar finding was also made by Calnan et al. (2001).

With regard to sources of stress, the women reported significantly higher scores. Out of the 28 items provided, the women obtained significant scores on eighteen of them. This result is consistent with that of Lim and Thompson (1996) in their study, on gender differences in occupational stress and coping strategies among IT personnel. In that study, the women reported significantly higher scores on sources of stress originating from "factors intrinsic to the job, managerial role, career achievement, organizational structure and climate and relationship with others". These findings are also consistent with those of Kariv (2007) and Korabik et al. (1993) in which they indicated that women encounter significantly more stressors than men. The results of the present study are instructive in that they seem to suggest that very little has changed since Davidson and Cooper's (1986) influential study on occupational stress among male and female managers two decades ago, and that of Lim and Thompson's (1996) study a decade ago. These stressors experienced by managerial women are likely to result in women's overall assessment of the job as being stressful.

A rather surprising finding is the fact that covert discrimination and favoritism failed to reach statistical significance, since previous studies (e.g., Broadbridge, 2000; Lim and Thompson, 1996) have revealed that women tended to be more likely to report stress originating from these factors. Research conducted in the West has shown that while a larger number of women are entering the work force, they are not necessarily moving up the ladder in terms of career advancement. Gender discrimination and the 'glass ceiling' effect have been some of the reasons cited in Western literature for the lack of visibility of women at the higher levels (e.g., Tzeng, 2006; Granleese, 2004; Lim and Thompson, 1996). The findings of the present study indicate that in different cultures, other explanations may hold good. Women's talents may be underutilized and there are strong individual and environmental barriers to career advancement. Also successful career women may not perceive themselves as underprivileged, even in a hostile culture. Thus, women who are in positions of power or have autonomous working situations fully expect their role to be demanding and tend to ignore suggestions of discrimination. Another plausible explanation is that in Ghana, enshrined in the 1992 constitution is a clause that prohibits any form of discrimination against any person. The Ghanaian situation appears not to have been institutionalized in that there are no wage differences and no overt attempt to prevent women's progress. Therefore this might have been the reason why an open form of this phenomenon is not evident; reflecting in the women's response. However, an instructive finding from the interview is that women managers tended to have inherent disadvantage in career progression. They indicated that since they operated in a result-oriented environment, and since achievement is pegged against target, to make it to the top means to forgo familiar responsibilities.

The quantitative results revealed that the women cited fear of falling behind technologically as a major source of stress. Rapid advances in technology have resulted in the need to keep up with the latest ideas, challenges and innovations and technology to meet organizational expectations. These brought about added pressures to female managers work demands. These women perceive it as a major source of stress probably because they feel greater pressure to achieve and to prove that they are knowledgeable and competent in a traditionally male-dominated field. Inevitably, this generates considerable stress to them as they tend to have a strong need to prove themselves in their job environment. This was also evident in the interview results. This finding is also consistent with that of Ogden et al. (2006), Granleese (2004) and also Davidson et al. (1995) who reported that women perceived their sex as a disadvantage in their careers and had experienced prejudiced attitudes and felt the need to perform better than the opposite sex in order to succeed at the same level. All these can be ascribed to the view of career theory being based on male values (Dalton, 1989).

Both the quantitative and qualitative data revealed that the women managers reported significantly higher scores on certain stress factors such as feeling isolated; inadequate feedback about my performance; insufficient resources and finance to work with; staff shortage and turnover rates; and too much responsibility as having the greatest impact on their mental health. Consistent with the results of the present study in which the women indicated that they often have to work with inadequate resources and finance, is the literature of Rout (1999) who also found among women general practitioners and practice managers that fund holding (not getting enough to work with) was a factor that was a great source of stress and which also impacted negatively on their mental well-being. Scasse and Goffee (1989) also indicated that resource scarcity was a great source of stress which also impacted negatively on women's health. Broadbridge (2000) as well as Rout (1999) also found that female managers reported too much responsibility as great source of stress that impacted negatively on their mental health. The current study's findings may reflect the trend towards the increased participation of women in the managerial positions (Wilson, 1995). This might have contributed to their feelings of too much responsibility particularly where the women are combining the multiple roles of work and home, and also reflect the major contribution of women's jobs and pay towards the household income. In addition the interview results also offer another plausible explanation, where the women indicated lack of training as explaining this phenomenon.

Although the women reported the least stress from feeling isolated, they were also significantly more likely to report that this factor impacted negatively on their overall mental health. Perhaps because these women's jobs involved interacting with people, a plausible explanation could be that majority of the women could have been type "A" since people with high type A tendencies pursue life in such an over-involved and driven manner as to not consciously be aware of day-to-day stressors/anxieties. In the interview, the women indicated that they experience a high level of job involvement and they enjoy their work. Therefore the frenetic pace of their lives may not allow for time to assess their entire job situation as stressful. Thus when asked on a self-report questionnaire if they feel isolated, they reported 'no'. Besides they may need to conceptualize their feelings as stimulation and challenging in order to be able to continue their very high levels of commitment to their work. Thus far, regardless of self-reports of low stress by the managerial women, there is cause for concern about their health risks.

The findings of this study also indicate that contemporary Ghanaian managerial women represent a mixture of traditional values and social patterns preserved by its culture. Majority of the women have children. These female managers have not forgone or postponed having children in preference for developing their careers. The women have a value system that reinforces a family orientation rather than an individualistic orientation. These women have been careful in not upsetting the delicate balance between home and career. However, this combination is somewhat affecting their personal health balance. These observations are consistent with that of Davidson et al. (1995) who indicated that the role of parent was a major source of stress for women in the middle years. Role strain increases when women are dissatisfied with childcare arrangements; for women, work often buffer marital stress, but parenthood exacerbates occupational stress (McBride, 1990; Rao et al., 2003). 


\section{Conclusions}

The great majority of the studies on occupational stress and health to date have concentrated on managerial women in developed countries. However, managerial women in developing cultures have been largely neglected. Thus understanding whether and under what conditions work stressors contribute to negative psychological health outcomes continues to be an important emphasis for workplace research. A number of findings from the analyses have relevance to the growing knowledge base regarding work-related risk and protective processes. The results indicated that there is a significant positive relationship between stress and mental health. In other words, the level of job stress was the best predictor of degree of depression, anxiety and physical symptoms. That is, the more stressors the women reported as experienced the greater mental health problems they reported. This study has therefore shown that while a definite amount of stress can be helpful to both an individual and the organization by stimulating them to creativity and action, the implications of too many job stressors can lead to harmful outcomes which can have grave implications for the health and safety of the working woman. It is also established that the managerial woman may suffer a range of mental illness, from minor ailments to fatal diseases (Cooper et al., 1997), and these can contribute to organizational deficiency by way of unpleasant feelings about their jobs and subsequent labor turnover.

The study has shown that a number of the stressors being experienced by managerial women are causing psychological strains and high turnover. Since these strain symptoms are predictors of ill-health, there is cause for concern for the health prognosis of women managers. From an organizational perspective, these strain symptoms must surely be affecting the job performance of these managers. Such stress symptoms as being unable to concentrate; becoming less communicative, feeling tense, uptight, tired, low energy, excessive fatigue; and job dissatisfaction are indications that they are probably not performing at the high level required by their demanding and critical job. Furthermore, since these stressors predict future ill-health, organizations should be concerned that the women managers' job performance may deteriorate in the future. The intriguing finding that strain symptoms decrease with the age of the women may mean either that these women adapt to the strains with age or that these managers are leaving their jobs just when they become most knowledgeable and valuable to their organizations in their roles as managers; where the latter explanation is true, organizations are paying a high price for the stress their women managers are experiencing.

\section{Recommendations}

Based on the conclusions of this study, it is important for organizations to realize the high price they pay for the stresses that their women managers experience, and which impact negatively on their mental health, and by implication their productivity the workplace. Since organizations view their human resource as a capital, and which quality and sustenance require continual development, it thus becomes imperative for organizations to learn to deal with those constraints that their female managers encounter. In this regard, therefore, it is recommended that organizations give due considerations to the following remedial measures which can help enhance the managerial capacity and competence of female managers at the workplace.

i. Organizations must have regular consultations with their female managers in order to be abreast with their changing needs which can then be aligned to those of the organization to allow for the optimization of available organizational resources available to their mutual benefits. Understanding of the human and his/her environment is the main issue here. The organizations must understand the individuals in relation to his/her work environment in order to improve individual work. In this regard, therefore, the individual needs and demands of the female managers must be respected and leveraged, so that they can have stress-free mindsets in the performance of their jobs.

ii. Organizations should also enhance social relations by putting in place structures and mechanisms (such as tea/coffee short breaks) that motivate and encourage social mix and positive organizational interaction among their human resources (both males and females).

iii. All female employees of organizations, whether managerial or non-managerial, should be provided with a systematic orientation when they first join the organization. New comers have much to learn about their supervisors and co-workers, the job demand and company rules and procedures, and the organization's culture and mission/vision. When employees learn enough to feel comfortable in these areas, it is highly unlikely that they will experience uncertainty and, by implication stress.

iv. Organizational design informs the character of information flow and feedback systems. Organizations must, therefore, put in place effective structures and mechanisms to enhance communication between the female managers and their superiors as well as their subordinates.

\section{References}

Beatty, C.A., 1996. The stress of managerial and professional women: is the price too high? Journal of Organizational Behaviour 17 (3), 233-251.

Beck, A.T., Steers, R.A., 1990. Beck Anxiety Inventory Manual. The Psychological Corporation, San Antonio, TX.

Broadbridge, A., 2000. Stress and the female retail manager. Women in Management Review 15 (3), 145-156.

Brown, T.A., Chorpita, B.F., Korotitsch, W., Barlow, D.H., 1997. Psychometric properties of the Depression Anxiety Stress Scales (DASS) in clinical samples. Behaviour Research and Therapy 35, 79-89.

Calnan, M., Wainwright, D., Forsythe, M., Wall, B., Almond, S., 2001. Mental health and stress in the workplace: the case of general practice in the UK. Socia Science \& Medicine 52 (4), 499-507.

Caplan, R.D., 1983. Person-Environment Fit: Past, Present and Future: Stress Research. Wiley, New York.

Caplan, R.D., Harrison, R.V., 1993. Person-environment fit theory. Some history, recent developments and future directions. Journal of Social Issues 49, 253-275.

Cohen, J.W., 1988. Statistical Power Analysis for the Behavioural Sciences, second ed. Lawrence Erlbaum Associates, Hillsdale, NJ.

Cooper, C.L., Marshall, J., 1978. Stress at Work. John Wiley, New York.

Cooper, C.L., Melhuish, A., 1984. Executive stress and health: differences between men and women. Journal of Occupational Medicine 26 (2), 99-104.

Cooper, C.L., Sloan, S.J., Williams, S., 1997. In: Cooper, C.L., Payne, R. (Eds.) Causes, Coping and Consequences of Stress at Work. Wiley, Chischester, England, pp. 375-411.

Cooper, C.L., Sloan, S.J., Williams, S., 1988. Occupational Stress Indicator. ASE, Windsor.

Dalton, G.W., 1989. Developmental views of careers in organizations. In: Arthur, M.B. Hall, D.T., Lawrence, B.S. (Eds.), Handbook of Career Theory. Cambridge University Press, Cambridge, pp. 89-109.

Davidson, M.J., Cooper, C.L., 1986. Executive women under pressure. International Review of Applied Psychology 35, 301-326.

Davidson, MJ., Cooper C.L., Baldini, V. 1995. Occupational stress in female and male graduate managers: a comparative study. Stress Medicine 11,157-175.

Freedman, S.J.M., 1990. Managing Lives. The University of Massachusetts Press, Amherst.

Gabriel, R., 1990. The validity of qualitative market research. Journal of the Market Research Society 32 (4), 507-519.

Ganster, D.C., Schaubroeck, J., 1991. Work stress and employee health. Journal of Management 17, 235-271.

Glowinkowski, S.P., Cooper, C.L., 1987. Managers and Professionals in Business Industrial Settings: the Research Evidence. Organizational Studies in Stress. Haworth Press, New York.

Granleese, J., 2004. Occupational pressures in banking: gender differences. Women in Management Review 19 (4), 219-226. 
Kamau, C.W. Burnout, locus of control and mental health of teachers in Eastern Province of Kenya. Unpublished Doctoral Thesis in Education Submitted to Punjab University, Chandigarh, 1992.

Korabik, K., McDonald, L., Rosin, H., 1993. Women, Work, and Coping. Mcgill Queen's University Press, Buffalo, NY.

Kariv, D., 2007. Linking the emotional reactions to coping: a closer look at gender differences among Israeli managers. International Journal of Work Organisation and Emotion 2 (2), 111-128.

Labour Act. Act 65/Risk to Health, 2003 Ghana.

Lazarus, R.S., Folkman, S., 1984. Stress, Appraisal, and Coping. Springer, New York. Lim, V.K.G., Thompson, S.H., 1996. Gender differences in occupational stress and coping strategies among information technology personnel. Women in Management Review 11 (1), 20-28.

Lovibond, S.H., Lovibond, P.F., 1995. Manual for the Depression Anxiety Stress Scales, second ed. Psychology Foundation, Sydney.

Manning, M.R., Jackson, C.N., Fusilier, M.R., 1996. Occupational stress, social support and the costs of health care. The Academy of Management Journal 39 (3), 738-750.

McBride, A.B., 1990. Mental health effects of women's multiple roles. American Psychology 45, 381-384.

Nieuwenhuijsen, K., de Boer, A.G., Verbeek, J.H., Blonk, R.W., van Dijk, F.J. The Depression Anxiety Stress Scales (DASS): detecting anxiety disorder and depression in employees absent from work because of mental health problems, 1995 (MEDLINE).

Ogden, S.M., McTavish, D., McKean, L., 2006. Clearing the way for gender balance in the management of the UK financial services industry: enablers and barriers. Women in Management Review 21 (1), 40-53.

Offerman, L.R., Gowring, M., 1990. Organisations of the future: changes and challenges. American Psychologist 45, 95-108.
Pisarski, A., Bohle, P., Callan, V.J., 1998. Effects of coping strategies, social support and work-nonwork conflict on shift worker's health. Scandinavian Journal of Work Environment and Health 24, 141-145.

Quick, J.C., Quick, J.D., 1984. Organizational Stress and Preventive Management. McGraw-Hill, New York.

Quick, J.C., Quick, J.D., Nelson, D.L., Hurrell, J.J., 1997. Preventive Stress Management in Organizations. American Psychological Association, Washington, DC.

Rao, K., Apte, M., Subbakrishna, D.K., 2003. Coping and subjective wellbeing in women with multiple roles. Journal of Social Psychiatry 49 (3), 175-184.

Rick, J., Briner, R.B., Daniels, K., Perryman, S., Guppy, A., 2001. A Critical Review of Psychosocial Hazard Measures. Contract Research Report 356/2001. Health and Safety Executive (HSE). The Institute for Employment Studies, Norwich, UK.

Rout, U.R., 1999. Occupational stress in women general practitioners and practice managers. Women in Management Review 14 (6), 220-230.

Scasse, R., Goffee, R., 1989. Reluctant Managers: Their Work and Life Style. Unwin Human, London.

Snow, D.L., Swan, S.C., Raghavan, C., Connell, C.M., Kleins, I., 2003. The relationship of work stressors, coping and social support to psychological symptoms among female secretarial employees. Work and Stress 17 (3), 241-263.

Tzeng, R., 2006. Gender issues and family concerns for women with international careers: female expatriates in Western multinational corporations in Taiwan. Women in Management Review 21 (5), 376-392.

Wells, J.A., 1982. Objective job conditions, social support and perceived stress among blue collar workers. Journal of Occupational Behaviour 3 (1), 79-94.

Williams, S., Cooper, C.L., 1998. Measuring occupational stress - development of the pressure management indicator. Journal of Occupational Health Psychology 3 (4), 306-321.

Wilson, F.M., 1995. Organizational Behaviour and Gender. McGraw-Hill, UK. 